\title{
The mechanism of azide activation of polyphenol oxidase II from tobacco ${ }^{\star}$
}

\author{
Chunhua Shi ${ }^{1}$, Qingliang Liu ${ }^{1 凶}$, Ya Dai $^{2}$, Yongshu $\mathrm{Xie}^{1}$ and Xiaolong $\mathrm{Xu}^{1}$ \\ ${ }^{1}$ Department of Chemistry, University of Science and Technology of China, Hefei, 230026, \\ P. R. China; ${ }^{2}$ Chongqing Tobacco Industrial Corp. Ltd., Chongqing, P. R. China
}

Received: 02 August, 2002; revised: 13 November, 2002; accepted: 05 December, 2002

Key words: polyphenol oxidase (PPO), azide activation, peroxide activation, superoxide activation, copper proteins

\begin{abstract}
So far, azide has been consistently reported to act as an inhibitor of metal enzymes, especially copper proteins. The present work shows that azide can also act as an activator of polyphenol oxidase II (PPO II) from tobacco leaves. From the square-wave voltammetry of native PPO II, peroxide-PPO II complex and azide-PPO II complex, the reduction of nitro blue tetrazolium by the enzymes and activation of PPO II by peroxide it follows that the binding of azide to PPO II induces the formation of $\mathrm{CuO}_{2}{ }^{2-} \mathrm{Cu}$ in the active site of PPO II from $\mathrm{CuO}_{2}{ }^{-} \mathrm{Cu}$ in native PPO II. The reason for azide acting as an activator can be attributed to azide complexing with PPO II, thus inducing the formation of $\mathrm{CuO}_{2}{ }^{2-} \mathrm{Cu}$, which is the active site of the peroxide-PPO II complex in which peroxide plays the role of activator.
\end{abstract}

Polyphenol oxidases (PPO) are a group of copper-proteins distributed widely over the whole phylogenetic scale from bacteria to mammals (Robb, 1984). The common feature of this group is their capacity to catalyze the oxidation of polyphenols by molecular oxygen (Malmström et al., 1975). PPO II (EC 1.10.3.1) has been successfully purified from Nicotiana tabacum (Shi et al., 2001a, 2002). It has a molecular mass of $35600 \mathrm{Da}$ and contains two antiferromagnetically coupled copper ions. The optimum $\mathrm{pH}$ and optimum temperature of PPO II are about $\mathrm{pH} 6.5$, and $40^{\circ} \mathrm{C}$, respectively. PPO II does not catalyze the oxidation of $p$-diphenol or $m$-diphenol, and shows only a low activity towards a polyphenol-chlorgenic acid (Shi et al., 2002).

So far azide was always reported to act as an inhibitor of PPO since it can form complexes with many copper enzymes (Gromov et al.,

\footnotetext{
${ }^{\text {This }}$ research was financially supported by the National Natural Science Foundation of China (No. 30270321) and foundation of University of Science and Technology of China.

${ }^{凶}$ To whom correspondence should be addressed: e-mail: qliu@ustc.edu.cn
}

Abbreviation: PPO, polyphenol peroxidase. 
1999; Sheline \& Strothkamp, 1980; Palmieri et al., 1997). There are three kinds of structures that azide coordinating with coppers can adopt i.e. $\mu-1,3$, terminal and $\mu-1,1$ coordination modes (Pate et al., 1989). The stearoylacyl carrier protein Delta desaturase (Delta(9)D) (Ai et al., 1997) coordinates azide by two different modes eta(1)-terminal at $\mathrm{pH}$ 7.8 and $\mu-1,3$ at $\mathrm{pH}<7.0$, as concluded from the Raman experiments of $\mathrm{N}_{3}{ }^{-}$asymmetric stretch (Ai et al., 1997). The interaction of azide with oxidized form of cytochrome $c$ oxidase from Paracoccus denitrificans shows that azide binds in two modes: a high-affinity mode $\left(K_{\mathrm{d}}=4.1 \mu \mathrm{M}\right)$ in which it is bound to a nonmetal site near the binuclear center, and a low-affinity mode $\left(K_{\mathrm{d}}=11.4 \mathrm{mM}\right)$ in which it is bound as a bridge to the binuclear center (Li et al., 1993; Vamvouka et al., 1999). Cytochrome bo oxidase from Escherichia coli binds azide also in two different conformations, each forming a bridging complex between heme $\mathrm{O}(3)$ and $\mathrm{Cu}-\mathrm{B}$ (Varotsis \& Vamvouka, 1999), this is at variance with the report that azide binds as a terminal ligand to $\mathrm{CuB}$ (Little et al., 1996). The azide bridges with the type- 2 and one type- 3 coppers in the type- 2 and type- 3 trinuclear site of laccase as a $\mu-1,3$ bridging ligand (Sheline \& Strothkamp, 1980; Cole et $a l .$, 1990; Pate et al., 1989).

Azide's toxicity to a metal enzyme, especially a copper enzyme, is mainly due to its strong coordination ability with the metal in the active site, which changes the coordination number and conformation of the active site, and depredates the active center metal. In the reaction between the copper amine oxidase and azide, azide probably hinders ligation of the precursor tyrosine to the copper. This prevents the formation of this key intermediate and inhibits the activity of the oxidase (Schwartz et al., 2001). On the other hand, it has been reported that azide partially protects the enzyme (50\%) against the loss of copper(I) and inactivation up to one anion per copper ion (Jewett et al., 2000). This finding suggested that azide might have a so far unknown function in its interaction with metal enzymes. In fact PPO II from tobacco was found to be activated by azide at a low concentration, at variance with other reports that azide always acts as an inhibitor of copper enzymes. It binds azide in the terminal mode as judged from the FT-IR of $\mathrm{N}_{3}{ }^{-}$asymmetric stretch and the absorbance increase at $410 \mathrm{~nm}$ (Shi et al., 2001c). Here we will discuss the mechanism by which azide activates PPO II, that is the mechanism of a novel function of azide in action with a copper enzyme.

\section{EXPERIMENTAL PROCEDURES}

Materials. Fresh tobacco leaves (Nicotiana tabacum) were harvested directly from the field, washed and kept in refrigerator below $4^{\circ} \mathrm{C}$ for about $24 \mathrm{~h}$. DEAE-Sephadex A-50, CM-Sephadex C-50 and Sephadex G-75 were purchased from Pharmacia Corporation (Sweden). Nafion solution (5\% ethanol solution) was purchased from Sigma Corporation (U.S.A.). Other chemicals were of analytical grade.

Protein preparation. Polyphenol oxidase II was prepared using the efficient method of extraction with acetone powder, followed by $30 \%$ and $80 \%$ ammonium sulfate precipitation and then column chromatography on DEAESephadex A-50, CM-Sephadex C-50 and Sephadex G-75 (Shi et al., 2001a). The purity of the enzyme was proved by SDS/PAGE and MALDI-TOF-MS (Shi et al., 2002). One unit of enzyme activity was defined as the amount of enzyme that caused an absorbance increase of 0.01 unit per minute at $420 \mathrm{~nm}$. Protein concentration was determined according to Bradford (1976) using BSA as a standard protein.

Square-wave voltammetry. The electrochemical measurements were performed on LK 98 Microcomputer-based Electrochemical System. A three-electrode compartment cell was used for the square-wave voltammetry. A glassy carbon (GC) electrode (4 $\mathrm{mm}$ in diameter) was used as the working electrode, a plati- 
num plate $(\mathrm{Pt})$ as counter electrode and an $\mathrm{Ag} / \mathrm{AgCl}$ electrode as reference electrode. Prior to each experiment, the GC electrode surface was carefully polished with diamond paste, rinsed thoroughly with doubly distilled water and dried in the air. The film of PPO II on the GC electrode was prepared as follows: $3 \mu \mathrm{l}$ of $20 \mathrm{mg} / \mathrm{ml}$ PPO II sample and $3 \mu \mathrm{l}$ of nafion stock solution (5\%) was thoroughly mixed, coated on the surface of GC electrode, and dried in air at $4^{\circ} \mathrm{C}$ for $6 \mathrm{~h}$. The $1: 1$ azide-PPO II and 4:1 azide-PPO II complexes were prepared by dialysis against deionized water for $5 \mathrm{~h}$. Peroxide-PPO II complex was prepared by adding $1 \mathrm{mM} \mathrm{\textrm {H } _ { 2 } \mathrm { O } _ { 2 }}$ to the electrolyte solution.

The reduction of nitro blue tetrazolium. The formation of $\mathrm{O}_{2}{ }^{-}$radicals was studied by monitoring the electrochemical reduction of nitro blue tetrazolium. The experiment was performed in $0.1 \mathrm{M} \mathrm{H}_{3} \mathrm{PO}_{4} / \mathrm{NaOH}$ buffer, $\mathrm{pH}$ 6.5 , at nitro blue tetrazolium concentration of $0.2 \mathrm{mM}$. The electrochemical system was as same as above. The electrolyte contained $0.033 \mathrm{mg} / \mathrm{ml}$ native PPO II, $0.033 \mathrm{mg} / \mathrm{ml} \mathrm{1:1}$ azide-PPO II complex and $0.033 \mathrm{mg} / \mathrm{ml}$ peroxide-PPO II complex. The cycle was repeated 4000 times, then the solution was scanned by Lambda 14 (Perkin Elmer) spectometr at the scan rate of $480 \mathrm{~nm} / \mathrm{s}$.

The activity of PPO II complex. This was determined by measuring PPO activity. For this purpose $10 \mu \mathrm{l}$ of PPO II solution (1 $\mathrm{mg} / \mathrm{ml}), 10 \mu \mathrm{l}$ of PPO II solution containing 10 -fold molar excess of $\mathrm{H}_{2} \mathrm{O}_{2} \mathrm{~m} / \mathrm{m}\left(2.8 \times 10^{-9}\right.$ $\mathrm{M} \mathrm{H}_{2} \mathrm{O}_{2}$ ) and 1 or 4 times as much azide were added to $50 \mathrm{mM}$ catechol in $50 \mathrm{mM}$ $\mathrm{H}_{3} \mathrm{PO}_{4} / \mathrm{NaOH}$ buffer, $\mathrm{pH}$ 6.5. The increase of absorbance at $420 \mathrm{~nm}$ with time was recorded.

The determination of $\mathrm{K}_{m}$ values. Five different concentrations of catechol substrate (1, $2,5,8,10 \mathrm{mM}$ ) were chosen to give measurable reaction rates. High concentrations of the substrate were not used to avoid fast polymerization of its oxidation product. The enzyme solutions of $10 \mu \mathrm{l} 1 \mathrm{mg} / \mathrm{ml}$ PPO II, $10 \mu \mathrm{l}$
$1 \mathrm{mg} / \mathrm{ml}$ PPO II containing 1:1 or $4: 1$ sodium azide, respectively, and $1 \mathrm{mg} / \mathrm{ml}$ PPO II containing $1 \mathrm{mM} \mathrm{H} \mathrm{H}_{2} \mathrm{O}_{2}$ were added to the substrate solution. The increase of absorbance was measured at $420 \mathrm{~nm}$ after $5 \mathrm{~min}$. The reaction rate was defined as the change of absorbance per minute.

\section{RESULTS AND DISCUSSION}

It is known from previous studies (Palmieri et al., 1997) that azide can form complexes with many copper enzymes, inhibiting their activity. The mechanism of inhibition is to prevent the formation of the key intermediate and thus to inhibit the activity of the enzyme (Schwartz et al., 2001) or to compete for the active site with another reacting molecule especially molecular oxygen (Pate et al., 1989; Cole et al., 1990). However, our experiment (see Fig. 1) gives evidence that at a low molar ratio of azide to PPO II, which is a novel polyphenol oxidase playing a key role in the plant defense system, the activity of PPO II increases with that ratio almost linearly and

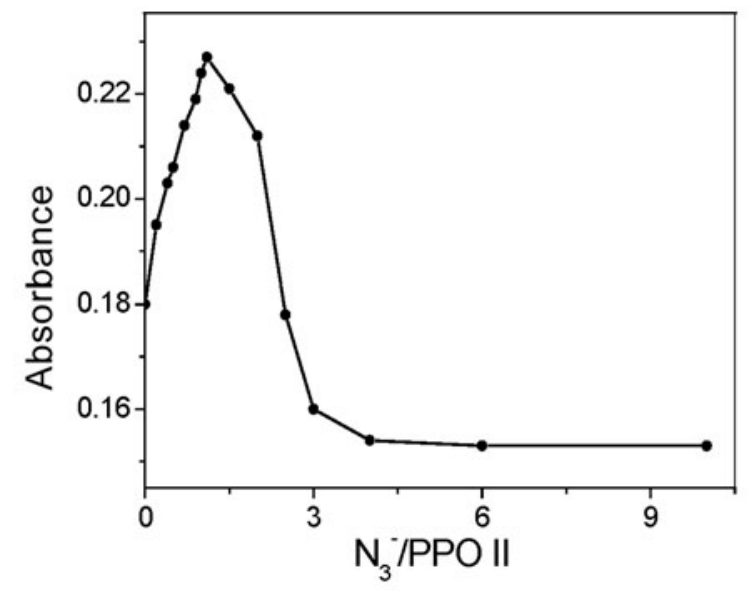

Figure 1. The effect of $\mathrm{N}_{3}{ }^{-}$on the activity of PPO II.

The samples of azide-PPO II complex sample were prepared at the azide to PPO II molar ratio of $0,0.2,0.4$, $0.6,0.7,0.8,0.9,1.0,1.1,1.2,1.5,2.0,3.0,4.0,6.0$ and 10.0 , respectively. The protein concentration was $0.033 \mathrm{mg} / \mathrm{ml}$. The absorbance of substrate solution at $420 \mathrm{~nm}$ was 0.079 when no enzyme was added to the reaction system. 
reaches a maximal value when the ratio equals one, while after that point it decreases until the activity vanishes at $\mathrm{N}_{3}{ }^{-}: \mathrm{PPO} \mathrm{II}=4$. This implies that azide can act as either an inhibitor or activator of the copper enzymes and its action depends only on its concentration. This result makes it necessary to look for the reason of activation by azide of a binuclear copper enzyme, like PPO II.

The FT-IR, UV/VIS and CD spectral determinations (Shi et al., 2001b) have demonstrated that a molecule of azide can bind with a pair of copper ions within the active site of PPO II in a terminal mode to form a complex. The reduction of nitro blue tetrazolium by $\mathrm{O}_{2}{ }^{-}$ superoxide radical leads to the formation of a blue-colored nitro blue formazan which can be determined by its visible absorption spectrum. Nitro blue tetrazolium can be electrochemically reduced by native PPO II, but not by $1: 1$ azide-PPO II complex or peroxide-PPO II complex (Fig. 2). This indicates that native PPO II can release the superoxide radical by catalyzing one-electron reduction of molecular oxygen in the solution, but 1:1

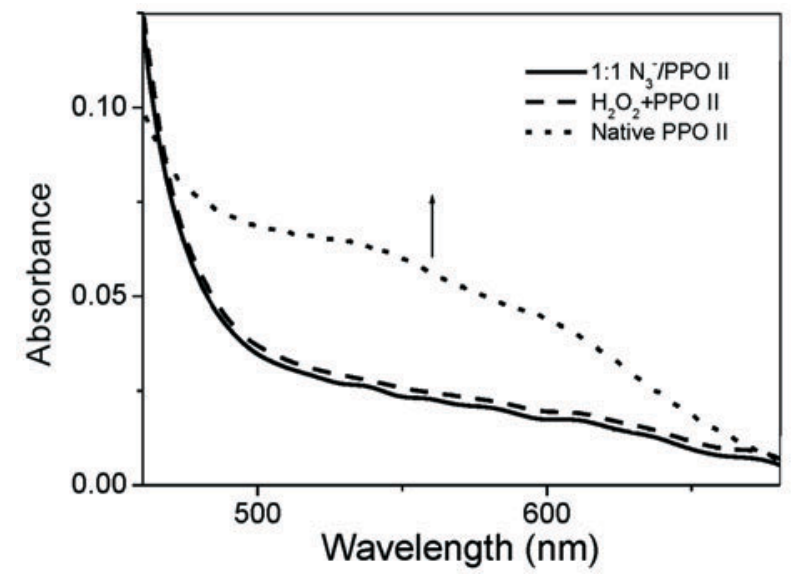

Figure 2. The electrochemical reduction of nitro blue tetrazolium by native PPO II, 1:1 azide complex and peroxide-PPO II complex.

The experiment was performed at nitro blue tetrazolium concentration of $0.2 \mathrm{mM}$ in $0.1 \mathrm{M}$ $\mathrm{H}_{3} \mathrm{PO}_{4} / \mathrm{NaOH}$ buffer, $\mathrm{pH}$ 6.5. The protein concentration was $0.033 \mathrm{mg} / \mathrm{ml}$. The cycle was repeated at 4000 times the scan rate of $500 \mathrm{mV} / \mathrm{s}$; the absorbance of solution was scaned at the rate of $480 \mathrm{~nm} / \mathrm{s}$.
azide-PPO II complex and peroxide-PPO II complex do not have this capacity.

Figure 3 shows the square-wave voltammetries of PPO II, azide-PPO II complex and

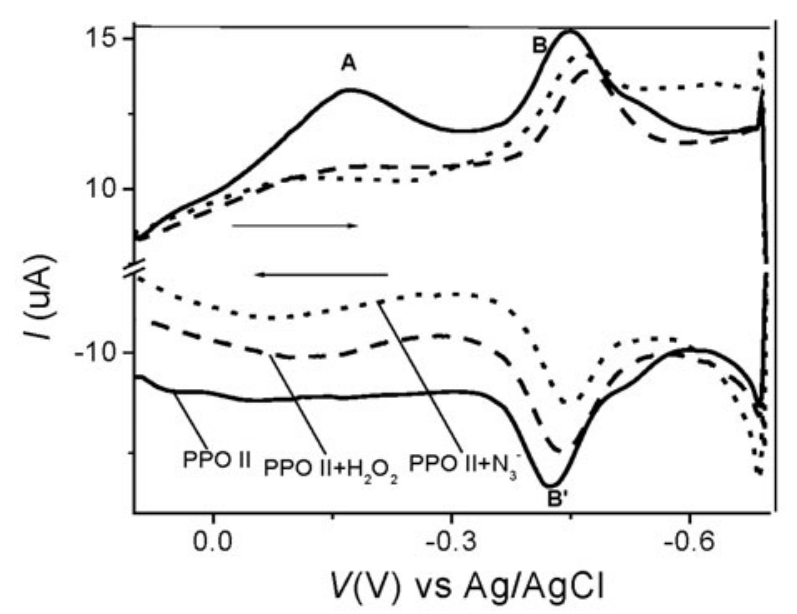

Figure 3. Square-wave voltammetry of native PPO II, peroxide-PPO II complex and azidePPO II complex.

Scanned at $\mathrm{pH} 6.5$, in $0.05 \mathrm{H}_{3} \mathrm{PO}_{4} / \mathrm{NaOH}$ buffer as the electrolyte. SW parameters were as follows: modulation amplitude, $25 \mathrm{mV}$; modulation period, $60 \mathrm{~ms}$; modulation steps, $2 \mathrm{mV}$; I, current intensity in $\mathrm{mA}$.

peroxide-PPO II complex. Native PPO II gives two cathodic peaks, $\mathrm{A}$ at $-0.182 \mathrm{~V}$ and $\mathrm{B}$ $(-0.450)$, and one anodic peak $\mathrm{B}^{\prime}(-0.424)$. Peak A, which disappears after the elimination of molecular oxygen and appears after the addition of molecular oxygen to the electrolyte, can be accounted for by one-electron transformation of the molecular oxygen, coordinated with binuclear copper ions in $\mu-\eta^{2}: \eta^{2}$ mode (Solomon et al., 1996; Eichen et al., 1999), to superoxide anion. This is evidenced by the reduction of nitro blue tetrazolium by native PPO II (see Fig. 2). The EPR signal also indicates that PPO II catalyzes oxidation of molecular oxygen to superoxide (not shown). The theoretical calculation also shows that PPO II catalyzes conversion of molecular oxygen to superoxide according to the following equation (Brookes et al., 1999). 


$$
\begin{gathered}
\mathrm{W}_{1 / 2}=(\mathrm{RT} / \alpha \mathrm{nF})\left\{3.61+13.73 \xi_{\mathrm{sw}}^{2} /\right. \\
\left.\left(\xi_{\mathrm{sw}}+38.13\right)\right\}
\end{gathered}
$$

Where $\xi_{\mathrm{sw}}=\mathrm{nFE}_{\mathrm{sw}} / \mathrm{RT} ; \alpha$, transfer coefficient; n, electron transfer number; F, Faraday constant; $\mathrm{E}_{\mathrm{sw}}$, half width of the peak.

The cyclic voltammogram also shows that there is an irreversible peak dependent on the presence of molecular oxygen in the electrolyte, which is assigned to the superoxide process (Tavagnacco et al., 1998). Peak B can be assigned to the reduction of the binuclear copper ions in the active site of PPO II because two electron transition can be explained in terms of the equation mentioned above (Brookes et al., 1999). It is widely accepted that peroxide strongly binds the pair of type-3 coppers in the $\mu-\eta^{2}: \eta^{2}$ coordination mode and the active site has the structure: $\mathrm{CuO}_{2}{ }^{2-} \mathrm{Cu}$ (Shi et al., 2001b; Solomon et al., 1996; Eichen et al., 1999; Rompel et al., 1999). When adding $\mathrm{H}_{2} \mathrm{O}_{2}$ to the reaction solution to form the peroxide-PPO II complex, the square wave voltammetry of the latter (Fig. 3) shows two changes, i.e., the disappearance of peak $\mathrm{A}$ and the shift of peaks B and $\mathrm{B}^{\prime}$ from $-0.450 \mathrm{~V}$ and $-0.424 \mathrm{~V}$ to $-0.471 \mathrm{~V}$ and $-0.443 \mathrm{~V}$, respectively. The disappearance of peak $\mathrm{A}$ is thought to be due to the formation of $\mathrm{CuO}_{2}{ }^{2-} \mathrm{Cu}$ from $\mathrm{CuO}_{2}{ }^{-} \mathrm{Cu}$ in the active site of PPO II (Shi et al., 2001; Solomon et al., 1996; Eichen et al., 1999; Rompel et al., 1999). The shift of peaks $\mathrm{B}$ and $\mathrm{B}^{\prime}$ result probably from the difference of the redox potentials of copper ions in the $\mathrm{CuO}_{2}{ }^{2-} \mathrm{Cu}$ and $\mathrm{CuO}_{2}{ }^{-} \mathrm{Cu}$ active site structures of PPO II. In the presence of oxygen in the electrolyte, PPO II catalyzes transformation of molecular oxygen to superoxide, which might form bonds with the pair of coppers in $\mu-\eta^{2}: \eta^{2}$ coordination mode, as the superoxide molecular bond length is similar to that of peroxide. The superoxide anion may quench immediately after the $\mathrm{Cu}$ (II) $\rightarrow \mathrm{Cu}$ (I) transformation because its distance from $\mathrm{Cu}(\mathrm{I})$ is about 5 Å (Solomon et al., 1996; Eichen et al., 1999;
Rompel et al., 1999) and superoxide bonds weakly with the pair of coppers, which can be caught by nitro blue tetrazolium from its product nitro blue formazan (Fig. 2). The distance of $2.9 \AA$ between the pair of $\mathrm{Cu}$ (II) (Solomon et al., 1996; Eichen et al., 1999; Rompel et al., 1999) makes it easy to coordinate the superoxide anion, which then becomes more stable than free superoxide anion in aqueous solution because the stability of the pair of coppers and the micro-environment of the active site. When azide is added, the square- wave voltammetry of its complex with PPO II (Fig. 2 ) is almost the same as that of peroxide-PPO II complex except the little shift of peaks B and $\mathrm{B}^{\prime}$ (from $-0.471 \mathrm{~V}$ and $-0.443 \mathrm{~V}$ to -0.467 $\mathrm{V}$ and $-0.440 \mathrm{~V}$, respectively). It is known that azide can coordinate with the copper ions in the enzymes and form three kinds of structures: terminal, $\mu-1,3$ and $\mu-1,1$ coordination modes (Pate et al., 1989) and the copper from PPO II can bond azide in the terminal mode (Shi et al., 2001c). The 1:1 azide-PPO II complex can not reduce the nitro blue tetrazolium to nitro blue formazan in the same way as does the peroxide-PPO II complex. Thus, we can imagine that $\mathrm{CuO}_{2}{ }^{-} \mathrm{Cu}$ in the native $\mathrm{PPO}$ II becomes transformed into $\mathrm{CuO}_{2}{ }^{2-} \mathrm{Cu}$ as the effect of azide coordination with a copper ion. This also means that the negative charge at the azide is transferred up to $\mathrm{O}_{2}{ }^{-}$at the $\mathrm{CuO}_{2}{ }^{-} \mathrm{Cu}$ to become $\mathrm{CuO}_{2}{ }^{2-} \mathrm{Cu}$. Therefore the disappearance of peak $\mathrm{A}$ of the square-wave voltammetry of the azide-PPO II complex can be attributed to the same reason as in the case of the peroxide-PPO II complex, and the little shift of peak $B$ and $\mathrm{B}^{\prime}$ between the azide-PPO II and peroxide-PPO II complexes can be also related to the coordination environment of copper ions in the azide-PPO II and peroxide-PPO II complexes.

As for $\mathrm{CuO}_{2}{ }^{2-} \mathrm{Cu}$, it can catalyze the oxidation of diphenol to diquinone more effectively. Figure 4 exhibits the changes with time of the activities of native PPO II and the peroxidePPO II complex. It is obvious that peroxide is an activator of the reaction catalyzed by per- 


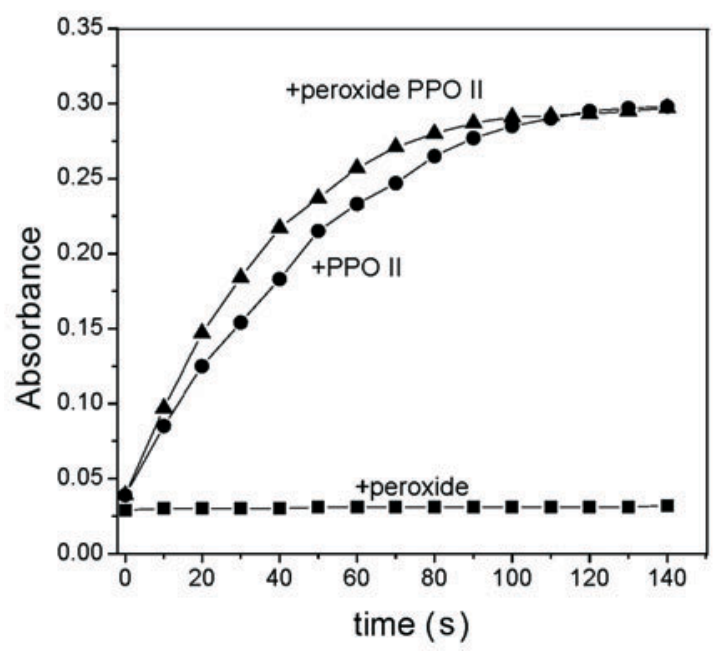

Figure 4. Changes in the activity of native PPO II and the peroxide-PPO II complex with time.

PPO II solution, $10 \mu \mathrm{l}(1 \mathrm{mg} / \mathrm{ml})$, and $10 \mu \mathrm{l}$ of PPO II solution containing $2.8 \times 10^{-9} \mathrm{~mol} \mathrm{H}_{2} \mathrm{O}_{2}$ were added to $50 \mathrm{mM}$ catechol in $50 \mathrm{mM} \mathrm{H} \mathrm{PO}_{4} / \mathrm{NaOH}$ buffer, $\mathrm{pH}$ 6.5. The increase in absorbance with time was recorded at $420 \mathrm{~nm}$ and the tangent to the interpolated line corresponds to the activity of the protein.

oxide-PPO II. Figure 5 shows the results of experiments aimed at estimation of $K_{\mathrm{m}}$ value of PPO II, 1:1, 4:1 $\mathrm{N}_{3}{ }^{-}$-PPO II complexes, and peroxide-PPO II complex. The $K_{\mathrm{m}}$ values are $54.2 \mathrm{mM}, 37.1 \mathrm{mM}, 196 \mathrm{mM}$ and $46.7 \mathrm{mM}$, respectively, at $10^{\circ} \mathrm{C}$, in $0.05 \mathrm{M} \mathrm{H}_{3} \mathrm{PO}_{4} / \mathrm{NaOH}$ buffer. It can be concluded that the respective intermediate of $\mathrm{CuO}_{2}{ }^{2-} \mathrm{Cu}$ is more effective than that of $\mathrm{CuO}_{2}{ }^{-} \mathrm{Cu}$ in the oxidation of as catechol substrate.

\section{CONCLUSIONS}

From the square-wave voltammetry and the reduction of nitro blue tetrazolium by native PPO II, by the azide-PPO II complex and peroxide-PPO II complex it follows that the azide-PPO II complex catalyzes transformation of oxygen to peroxide and not to superoxide as does the native PPO II. This result explains well that azide at a low concentration activates PPO II because the activity of the peroxide-PPO II complex is higher than that of native PPO II. The azide induces the formation of $\mathrm{CuO}_{2}{ }^{2-} \mathrm{Cu}$ which is the active

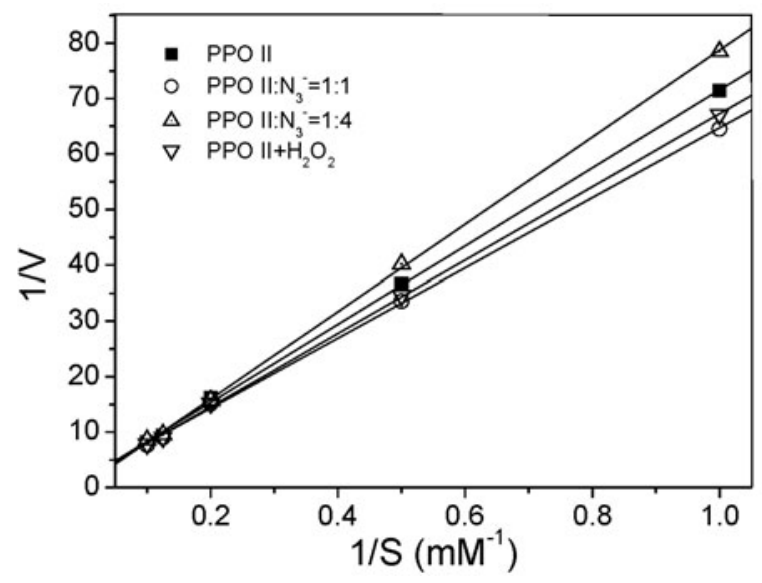

Figure 5. The estimation of $K_{\mathrm{m}}$ values of PPO II, azide-PPO II complexes (1:1 and 1:4) and peroxide PPO II.

The substrate (S) catechol was used at the concentration of $1,2,5,8$ or $10 \mathrm{mM}$ in $0.05 \mathrm{M} \mathrm{H}_{3} \mathrm{PO}_{4} / \mathrm{NaOH}$ buffer, $\mathrm{pH}$ 6.5. The enzyme solutions of $10 \mu \mathrm{l}$ PPO II. (1 mg/ml), $10 \mu \mathrm{l}$ PPO II ( $1 \mathrm{mg} / \mathrm{ml})$ containing $1: 1$ or 4:1 sodium azide or $1 \mathrm{mg} / \mathrm{ml}$ PPO II containing $1 \mathrm{mM}$ $\mathrm{H}_{2} \mathrm{O}_{2}$, were added to the substrate solution. The absorbance at $420 \mathrm{~nm}$ was determined after 5 min of the reaction carried at $10^{\circ} \mathrm{C}$. The reaction rate $\mathrm{V}$ is expressed as a change in absorbance per minute.

site of the peroxide-PPO II complex in which the peroxide intermediate plays the role of activator.

\section{R E F E R E N C E}

Ai JY, Broadwater JA, Loehr TM, Sandersloehr J, Fox BG. (1997) Peroxodiferric intermediate of stearoyl-acyl carrier protein Delta desaturase: oxidase reactivity during single turnover and implications for the mechanism of desaturation. J Biol Inorg Chem.; 2: $37-45$.

Bradford MM. (1976) A rapid and sensitive method for the quantitation of microgram quantities of protein utilizing the principle of protein-dye binding. Anal Biochem.; 72: 248-54.

Brookes BA, Ball JC, Compton RG. (1999) Simulation of square wave voltammetry: reversible electrode processes. J Phys Chem B., 103: 5289-98.

Cole JL, Clark PA, Solomon EI. (1990) Spectroscopic and chemical studies of the laccase 
trinuclear copper active site: geometric and electronic structure. J Am Chem Soc.; 112: 9534-48.

Eichen C, Krebs B, Saccbettini JC. (1999) Catechol oxidase-structure and activity. Curr Opin Struct Biol.; 9: 677-83.

Gromov I, Marchesiui A, Farver OI, Pecht I, Goldfarb D. (1999) Azide binding to the trinuclear copper center in laccase and ascorbate oxidase. Eur J Biochem.; 266: $820-30$.

Jewett SL, Olmsted HK, Marach JA, Rojas F, Silva K. (2000) Anion protection of CuZnSOD during peroxidative activity with $\mathrm{H}_{2} \mathrm{O}_{2}$. Biochem Biophys Res Commun.; 274: 57-60.

Li WB, Palmer G. (1993) Spectroscopic characterization of the interaction of azide and thiocyanate with the binuclear center of cytochrome-oxidase - evidence for multiple ligand sites. Biochemistry.; 322: 1833-43.

Little RH, Cheesman MR, Thomson AJ, Greenwood C, Watmough NJ. (1996) Cytochrome bo from Escherichia coli: binding of azide to Cu-B. Biochemistry., 35: 13780-7.

Malmström BG, Andreasson LE, Reinhammar B. (1975) In Enzymes. Boyer PD. ed. 12: 507-79. Academic Press, NY.

Palmieri G, Giardina P, Bianco C, Scaloni A, Sannia G. (1997) A novel white laccase from Pleurotus ostreatus. J Biol Chem.; 272: 31301-7.

Pate JE, Ross PK, Thamann TJ, Reed CA, Karlin KD, Thomas SN, Solomon EI. (1989) Spectroscopic studies of the charge transfer and vibrational features of binuclear copper(ii) azide complexes: comparison to the coupled binuclear copper active site in Met azide hemocyanin and tyrosinase. $J A m$ Chem Soc.; 111: 5198-209.

Robb DA. (1984) In Copper proteins and copper enzymes. Lontie R. ed, 2, 207-41. CRC Press, Boca Raton, FL.

Rompel A, Fischer H, Meiwes D, BuldtKarentzopoulos K, Dillinger R, Tuczek F, Witzel H, Krebs B. (1999) Purification and spectroscopic studies on catechol oxidases from Lycopus europaeus and Populus nigra: evidence for a dinuclear copper center of type 3 and spectroscopic similarities to tyrosinase and hemocyanin. J Biol Inorg Chem.; 4: 56-63.

Schwartz B, Olgin AK, Klinman JP. (2001) The role of copper in topa quinone biogenesis and catalysis, as probed by azide inhibition of a copper amine oxidase from yeast. Biochemistry.; 40: 2954-63.

Sheline R, Strothkamp KG. (1980) The pH dependence of the inhibition of ascorbate oxidase by anions. Biochem Biophys Res Commun.; 96: 1343-8.

Shi C, Dai Y, Xia B, Xu X, Xie Y, Liu Q. (2001a) the purification and spectral properties of polyphenol oxidase I from Nicotiana tabacum. Plant Mol Biol Rep.; 19: 381-2.

Shi C, Dai Y, Xu X, Xie Y, Liu Q. (2001b) UV/VIS spectra studies on the polyphenol oxidase II. (PPO II) from tobacco. Spectroscopy Lett.; 34: 675-83.

Shi C, Dai Y, Xu X, Xie Y, Han H, Liu Q. (2001c) Interaction between azide and PPO II from tobacco. J Protein Chem.; 20: 463-8.

Shi C, Dai Y, Xu X, Xie Y, Liu Q. (2002) The purification of polyphenol oxidase from tobacco. Protein Exp Purif.; 24: 51-5.

Solomon EI, Sundaram UM, Mochonkin TE. (1996) Multicopper oxidase and oxygenases. Chem Rev.; 96: 2563-605.

Tavagnacco C, Moszner M, Cozzi S, Peressinin S, Costa G. (1998) Electrocatalytic dioxygen reduction in the presence of a rhodoxime. $J$ Electroanalyt Chem.; 448: 41-50.

Vamvouka M, Muller W, Ludwig B, Varotsis C. (1999) Fourier transform infrared and resonance Raman studies of the interaction of azide with cytochrome $c$ oxidase from Paracoccus denitrificans. J Phys Chem B.; 103: $3030-4$.

Varotsis C, Vamvouka M. (1999) Resonance Raman and Fourier transform infrared detection of azide binding to the binuclear center of cytochrome bo(3) oxidase from Escherichia coli. J Phys Chem B.; 103: 3942-6. 